Article

\title{
Dispersion of Multi-Walled Carbon Nanotubes Stabilized by Humic Acid in Sustainable Cement Composites
}

\author{
Yuan Gao, Hongwen Jing *, Mingrui Du and Weiqiang Chen \\ State Key Laboratory for Geomechanics \& Deep Underground Engineering, \\ China University of Mining \& Technology, Xuzhou 221116, China; gaoyuan16@cumt.edu.cn (Y.G.); \\ dumingruicumt@sina.com (M.D.); ts16030036a3@cumt.edu.cn (W.C.) \\ * Correspondence: hongwenjingcumt@126.com; Tel.: +86-138-0520-9187
}

Received: 23 August 2018; Accepted: 19 October 2018; Published: 20 October 2018

\begin{abstract}
Multi-walled carbon nanotubes (MWCNTs) are promising nanoreinforcing materials for cement-based composites due to their superior material properties. Dispersion of MWCNTs is key for achieving the most effective way of enhancing efficiency, which is challenging in an alkaline cementitious environment. In this study, humic acid (HA) was used to stabilize the degree of dispersion of MWCNTs in an alkaline environment. The efficiency of HA in stabilizing MWCNT dispersion in cement composites was characterized using an ultraviolet spectrophotometer. The influences of HA on the workability and mechanical properties of ordinary Portland cement (OPC) reinforced with MWCNTs were evaluated, and the results revealed that the addition of HA can improve the stability of MWCNT dispersion in an alkaline environment. A concentration of $0.12 \mathrm{wt} . \% \mathrm{HA} / \mathrm{S}$ added to MWCNT suspensions was found to perform the best for improving the dispersion of MWCNTs. The addition of HA results in a decreased workability of the OPC pastes but has little influence on the strength performance. HA can affect the mechanical properties of OPC reinforced with MWCNTs by influencing the dispersion degree of the MWCNTs. An optimum range of HA $(0.05-0.10 \mathrm{wt} . \%)$ is required to achieve the optimum reinforcing efficiency of MWCNTs.
\end{abstract}

Keywords: humic acid (HA); MWCNT dispersion; stabilization; alkaline environment; cement

\section{Introduction}

Due to their high aspect ratio, low density [1,2], and superior mechanical [3], thermal [4], and electrical properties [5], multi-walled carbon nanotubes (MWCNTs) have proven to be quite efficient in reinforcing the material properties of organic polymers [6], biomaterials [7], and ceramics [8]. Recent studies [9-12] have shown that the superior material properties of MWCNTs make them promising candidates to be mixed into ordinary Portland cement (OPC) for the purpose of strength improvement and microstructure reinforcement. Zou et al. [13] added $0.075 \mathrm{wt} . \%$ of MWCNTs into OPC pastes and improved the flexural strength and elastic modulus by $63 \%$ and $32 \%$, respectively. Xu et al. [14] determined that MWCNTs can fill nano-scale gel pores between calcium silicate hydrate products and reduce the porosity of OPC pastes.

In order to achieve the maximum enhancing efficiency, MWCNTs should be dispersed individually in the final matrices [15]. Agglomerated MWCNTs function as defects that lead to stress concentration, resulting in the degradation of strength performance [9,13]. Pristine MWCNTs interact strongly with each other due to the van der Waals attraction $[16,17]$ and tend to form large agglomerates. Currently, MWCNT suspensions are generally used as alternatives to pristine MWCNTs for addition to matrices [18]. MWCNT suspensions are prepared by adding surfactants such as air entrainers, 
calcium naphthlaene sulfonate, and polycarboxylates under ultrasonication [18]. However, the stability of dispersed MWCNTs in aqueous solutions is challenging to achieve in the alkaline environment of cementitious mixtures [19]. In cementitious mixtures, surfactants will chemically react with ions (i.e., $\mathrm{Ca}^{2+}, \mathrm{Na}^{+}, \mathrm{K}^{+}, \mathrm{SO}^{4-}$, and $\mathrm{OH}^{-}$ions) $[20,21]$, thus the amount of surfactant molecules participating in the dispersion of MWCNTs will decrease, resulting in re-agglomeration of the MWCNTs. In previous studies [19], it has been found that re-agglomerated MWCNTs in fresh cementitious mixtures can reach over $80 \%$ after $18 \mathrm{~h}$. Du et al. [22] have found that methylcellulose can help to stabilize dispersed MWCNTs in an alkaline environment owing to the viscosity-increasing effect that retards the movement of MWCNTs. However, the in-situ applications of the prepared cementitious mixtures will be limited owing to the decreased workability, especially in conditions where high fluidity is required [15,23]. Workability is another significant factor for fresh OPC pastes in civil engineering, particularly grouting projects [23], which has a major influence on the transport of cement particles when the mixtures are fresh. Maintaining a high water-to-cement $(w / c)$ ratio has some benefits, such as increasing workability and reducing the carbon footprint [22]. Although lowering the $w / c$ ratio is one of the most common methods to increase the strength of cement pastes, benefits such as workability will suffer severely. Therefore, the introduction of well-dispersed MWCNTs into cementitious composites holds the potential to overcome the shortage of paste strength.

Humic acid (HA), a biological macromolecule, is one of the most common natural organic matters. It is neutral in aqueous solutions, environmentally-friendly, and non-toxic [24]. The mass content of hydroxy and phenolic hydroxyl functional groups in HA is generally lower than 1\% [25]. Strong steric repulsion forces exist between HA molecules [26]. Previous studies [27,28] have found that HA can absorb onto the surface of MWCNTs through electrostatic interaction, $\pi-\pi$ interaction, hydrophobic interaction, and hydrogen bonding, and the dispersion of MWCNTs in water can be stabilized due to the steric repulsion effect. Han et al. [26] have found that the addition of $0.005 \mathrm{wt}$.\% HA to $0.01 \mathrm{wt} . \%$ carbon black nanoparticles can increase the dispersion degree of carbon black nanoparticles in an aquatic environment by $78 \%$. Saleh et al. [25] have found that mixing $0.002 \mathrm{wt} . \% \mathrm{HA}$ in aqueous solutions could improve the colloidal stability of MWCNTs and reduce the re-aggregation rate by about two orders of magnitude. In work conducted by Yang et al. [29], HA was found to be quite effective in enhancing the dispersibility of nanobiochar in an alkaline aqueous medium with $\mathrm{pH}$ higher than 10. Since the steric repulsion effect of HA is not influenced by the alkaline environment [29] and the mass content of functional groups is so low that chemical reactions between HA and cement will not happen [24], HA holds the potential to be used to stabilize the dispersion of MWCNTs in cementitious composites.

In this paper, the stabilizing effect of HA on the dispersion of MWCNTs in OPC was experimentally studied. The dispersion degree of MWCNTs in simulated cementitious pore solutions and aqueous solutions containing HA was characterized using ultraviolet-visible spectrophotometry (UV-vis). The workability and mechanical properties of the MWCNT-enhanced OPC matrices were studied. The nanostructure of MWCNT-reinforced OPC matrices was investigated using a scanning electron microscope (SEM). The results of this study reveal that the addition of HA can improve the stability of MWCNT dispersion in an alkaline environment, with an increase of $21.9-45.8 \%$ compared to no HA. An optimum range of HA (0.05-0.10 wt.\%) can achieve the best enhancement efficiency of the mechanical performance of OPC reinforced with MWCNTs. The findings of this study provide a new method for improving the degree of dispersion of MWCNTs and guide further understanding of MWCNT-OPC composites.

\section{Experimental Process}

\subsection{Materials and Instrumentation}

OPC, type P.O. 42.5, referring to the requirements of Chinese Standard GB175-2007 [30], was used as the binder material in this study. The commercially purchased MWCNTs have an average diameter 
of 5-15 $\mathrm{nm}$ and an average length of 10-20 $\mu \mathrm{m}$. A commercial polycarboxylate-based surfactant (PC) was used as the dispersing agent to improve the dispersion degree of the MWCNTs in water [13]. HA containing two types of functional groups (i.e., hydroxy and phenolic hydroxyl) with a mass content of $0.9 \%$ was used.

A horn ultrasonicator (VCX 500W) (SONICS Inc., Newtown, CT, USA) with a 13-mm-diameter cylindrical tip was used to disperse the agglomerated MWCNTs in an aqueous solution.

UV-vis tests were performed using ultraviolet-visible spectrophotometry (TU-1901) (PERSEE Inc., Beijing, China) to characterize the dispersion degree of the MWCNTs.

The uniaxial compression and flexural tests of the specimens were carried out using a DNS100 electronic universal testing machine (Changchun research institute for mechanical science Co., Ltd, Changchun, China).

A scanning electron microscope (SEM, Su8200) (HITACHI Inc., Tokyo, Japan) was used to investigate the microstructure of the hardened MWCNT-OPC pastes.

\subsection{Preparation of MWCNT Suspensions}

The suspensions were prepared by mixing MWCNT powder with PC in distilled water under ultrasonication (Figure 1a). The ultrasonication power and time were fixed at $150 \mathrm{~W}$ and $15 \mathrm{~min}$, respectively. To prevent overheating, the suspensions were placed in an ice-water bath. According to previous studies $[13,19,22]$, the concentration of the MWCNT powder was defined as 0.08 wt.\% relative to the weight of the suspensions. The PC-to-suspension ratio was $0.64 \mathrm{wt} \%$, which was eight times the concentration of the MWCNTs.

(a)
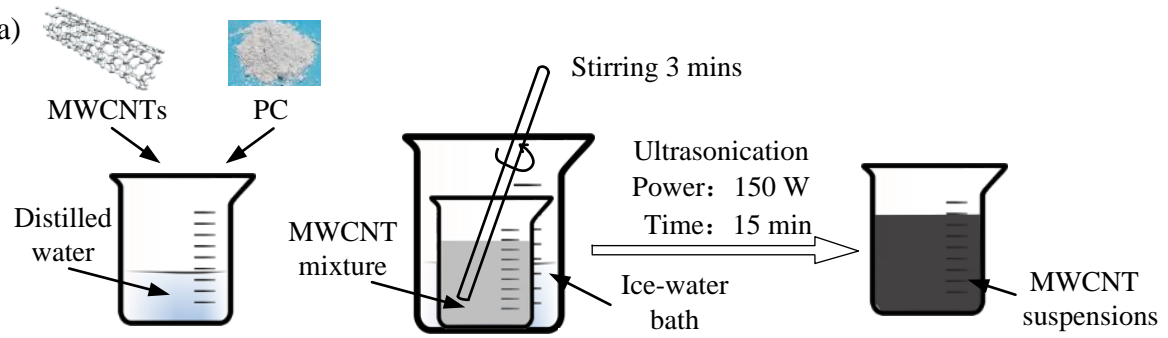

(b)

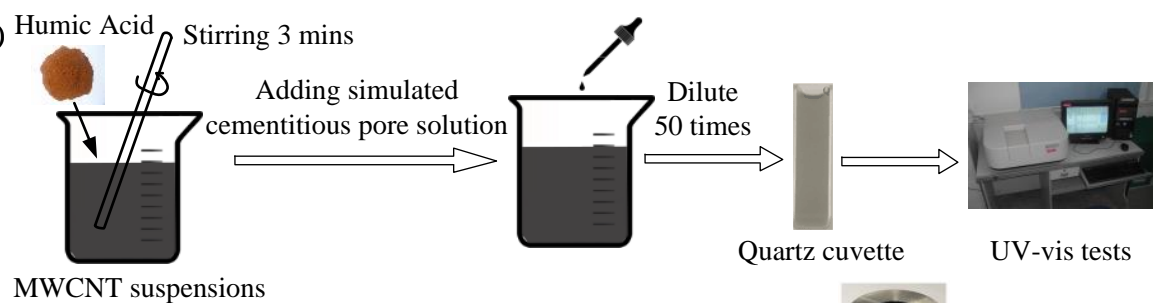

MWCNT suspensions

(c) Humic Acid Stirring 3 mins

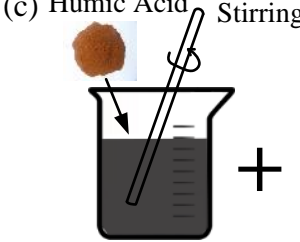

MWCNT suspensions
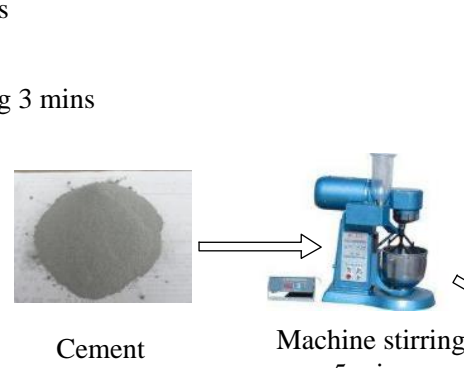

Machine stirring 5 mins

Fresh paste for mini-slump tests

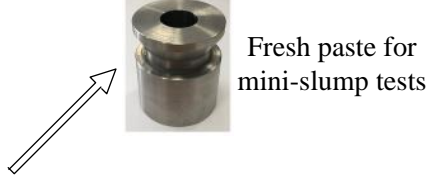

Temp $=20 \pm 5^{\circ} \mathrm{C} \quad \mathrm{RH}=95 \%$

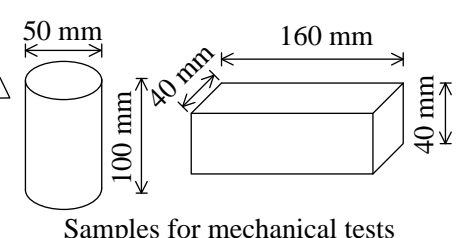

Samples for mechanical tests

Figure 1. Preparation of: (a) Multi-walled carbon nanotubes (MWCNT) suspensions; (b) MWCNT samples for UV tests; (c) MWCNT-OPC samples for mini-slump tests and the characterization of mechanical properties. 
As shown in Figure 1b, the MWCNT suspensions were first subjected to ultrasonication before adding the HA powder and stirring for 3 minutes [31]. The concentration of HA was defined by the weight ratio of the HA powder to the MWCNT suspension (HA/S), and four concentrations of $0.00 \mathrm{wt} . \%, 0.12 \mathrm{wt} . \%, 0.25 \mathrm{wt} . \%$, and $0.50 \mathrm{wt} . \%$ were designed, as exhibited in Table 1 . Both the preparation of the MWCNT suspensions and the dissolving of the HA powder were conducted at room temperature $\left(20 \pm 5{ }^{\circ} \mathrm{C}\right)$. To test the stabilization of the MWCNT suspensions in an alkaline environment, a simulated cementitious pore solution was added into the suspensions after ultrasonication. The concentrations of chemicals [21] in the simulated OPC pore solution are presented in Table 2. The composition of the cementitious pore solution provided the $\mathrm{Ca}^{2+}, \mathrm{Na}^{+}, \mathrm{K}^{+}, \mathrm{SO}^{4-}$, and $\mathrm{OH}^{-}$ions found in early-age (within $8 \mathrm{~h}$ ) concrete [20].

Table 1. Mix design of plain ordinary Portland cement (OPC) and multi-walled carbon nanotubeordinary Portland cement (MWCNT-OPC) pastes.

\begin{tabular}{ccccccc}
\hline Mix & C/S (wt.\%) & P/S (wt.\%) & HA/S (wt.\%) & C/G (wt.\%) & P/G (wt.\%) & HA/G (wt.\%) \\
\hline Ref & & & 0 & & 0 \\
MWCNTs-1 & & & 0 & & 0 \\
MWCNTs-2 & 0.08 & 0.64 & 0.12 & 0.032 & 0.256 & 0.05 \\
MWCNTs-3 & & & 0.25 & & & 0.10 \\
MWCNTs-4 & & & 0.50 & & & 0.20 \\
\hline
\end{tabular}

Note: $\mathrm{C} / \mathrm{S}$ and P/S represent MWCNT- and PC-to-suspension weight percentages. $\mathrm{C} / \mathrm{G}$ and $\mathrm{P} / \mathrm{G}$ represent MWCNT- and PC-to-cement weight percentages.

Table 2. Concentration of prepared chemicals in the simulated cementitious pore solution.

\begin{tabular}{ccccc}
\hline Compounds & $\mathrm{NaOH}$ & $\mathrm{KOH}$ & $\mathrm{CaSO}_{4} \cdot 2 \mathbf{H}_{2} \mathbf{O}$ & $\mathrm{Ca}(\mathrm{OH})_{2}$ \\
\hline Concentration $(\mathrm{g} / \mathrm{L})$ & 8 & 22.4 & 27.6 & Saturated \\
\hline
\end{tabular}

\subsection{Preparation of Specimens}

The specimens were cast in steel molds (50 $\mathrm{mm} \times 100 \mathrm{~mm}$ and $40 \mathrm{~mm} \times 40 \mathrm{~mm} \times 160 \mathrm{~mm}$ ) after mixing each solution (containing $0.00 \mathrm{wt} . \%, 0.05 \mathrm{wt} . \%, 0.10 \mathrm{wt} . \%$, and $0.20 \mathrm{wt} . \%$ of HA powder) and cement (using HA/G to represent the weight ratio of HA to cement; see Table 1). Then, the solutions and the cement powder were mixed based on a water-to-cement ratio $(w / c)$ of 0.4 (Figure $1 \mathrm{~b}$ ). Two types of specimens were prepared for the compressive and flexural strength tests. The samples were demolded after $24 \mathrm{~h}$ and cured in a saturated lime water bath at a temperature of $20 \pm 5{ }^{\circ} \mathrm{C}$ and a relative humidity of $95 \%$ for another $27 \mathrm{~d}$ before testing [22]. Aqueous solutions containing distilled water, PC, and HA powder were used to make the reference cementitious pastes (Ref pastes; see Table 1).

\subsection{Characterization}

\subsubsection{Dispersion Tests for MWCNT Suspensions}

The time-dependent stabilization of the prepared MWCNT suspensions in alkaline environments was characterized by UV-vis. The measured absorbance (ABS) at a certain wavelength can reflect the degree of dispersion [32,33]. The prepared solutions were diluted by a factor of 50 and tested at a wavelength $(\lambda)$ of $500 \mathrm{~nm}$ every hour up to $18 \mathrm{~h}$ after mixing to calculate the dispersed MWCNT concentration $\left(C_{d}\right)$. Although the cement paste hardening normally happens at about $3-4 \mathrm{~h}$, the initial setting time seriously delayed by higher $w / c$ and the environmental humidity, particularly in the underground grouting engineering projects [23]. Therefore, in this study, the UV-vis tests measured $0-18 \mathrm{~h}$ to ensure the cement paste hardened, which is consisted with previous research studies $[19,22]$. 
Three samples were measured in each UV-vis test to ensure that the concentration of MWCNTs in the solution was consistent. $C_{d}$ was calculated using Beer-Lambert's law [34-36], given as:

$$
C_{d}=\frac{A}{\varepsilon l}
$$

where $A$ is the average absorbance, $\varepsilon$ is the extinction coefficient [34-36], and $l=1 \mathrm{~cm}$ is the optical path length of the light through the MWCNT suspensions.

To determine $\varepsilon$, the well-dispersed suspensions with $0.08 \mathrm{wt} . \%$ MWCNTs were first diluted with distilled water by factors of 50,75, 100, 125, and 150 .

The above suspensions were thoroughly ultrasonicated to guarantee that the maximum ABS was reached. $\varepsilon$ was then determined by fitting a zero-intercept linear correlation between the measured $\mathrm{ABS}$ and the theoretical maximum concentration of the suspensions $\left(C_{\mathrm{t}}\right)$. The zero-intercept linear regression equation in Figure 2 suggests that $\varepsilon$ is $43.12 \mathrm{~mL} \mathrm{mg}^{-1} \mathrm{~cm}^{-1}$, which is consistent with the reported values between 41 and $46 \mathrm{~mL} \mathrm{mg}^{-1} \mathrm{~cm}^{-1}$ [34-36]. The goodness of fit is indicated by the correlation coefficient $\left(R^{2}\right)$ of the equation $(98.3 \%)$.

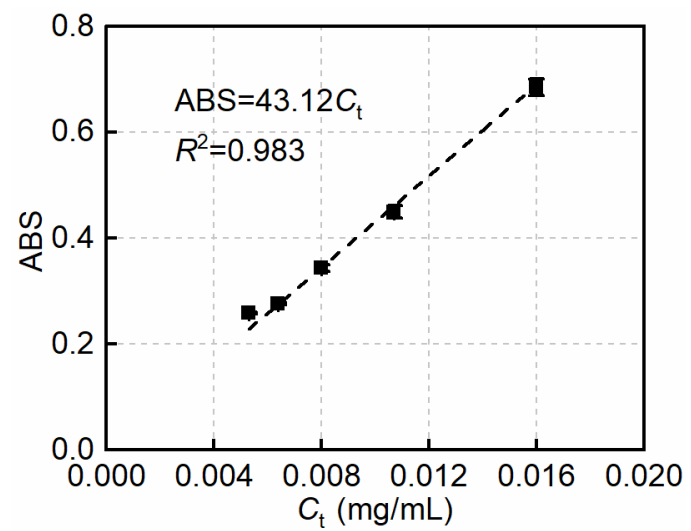

Figure 2. The zero-intercept linear relationship between absorbance (ABS) and $C_{t}$ in solutions at $\lambda=500 \mathrm{~nm}$.

\subsubsection{Characterization of Workability}

The workability of fresh MWCNT-OPC and plain OPC pastes was measured using mini-slump tests [18]. The setup and geometry of the mini-slump cone are presented in Figure 3. The cone was first placed on a flat sheet, then fresh paste was poured into the cone and compacted. The excess paste was then removed from the top surface, and the cone was lifted vertically to ensure minimal lateral disturbance during the tests. The diameter of the hardened spread samples was measured at five different locations around the outline after $24 \mathrm{~h}$. Workability was defined as the average measurement.

(a)

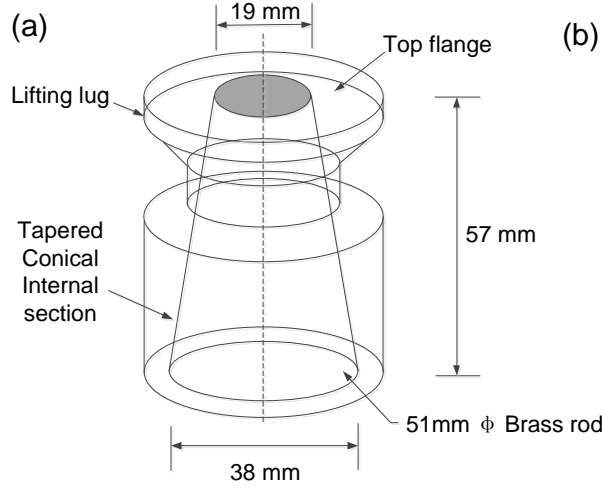

(b)

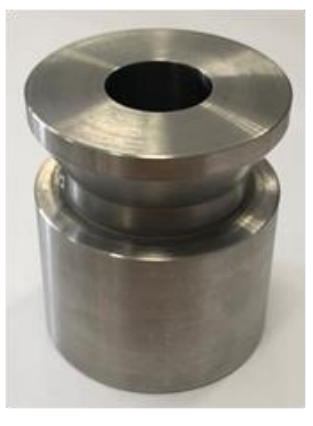

Figure 3. (a) Dimensions and (b) mini-cone for mini-slump test. 


\subsubsection{Mechanical Properties and Microstructure Tests}

The compressive strength $\left(\sigma_{\mathrm{c}}\right)$ of the MWCNT-OPC pastes were measured using a universal testing machine. Constant loading rates of $0.5 \mathrm{~mm} \mathrm{~min}^{-1}$ were adopted for the compressive strength tests. Three specimens were prepared and tested for each paste.

The flexural strength $\left(\sigma_{\mathrm{t}}\right)$, Young's modulus $(E)$, and fracture energy $\left(G_{\mathrm{F}}\right)$ of the cement pastes were measured using three-point bending tests [13], as presented in Figure 4. An extensometer with a gauge length of $50 \mathrm{~mm}$ and a $+5 \mathrm{~mm}$ measurement range was attached to the beam with a glue stick. A constant loading rate of $0.1 \mathrm{~mm} \mathrm{~min}^{-1}$ was adopted. Both the crack mouth opening displacement (CMOD) and the load line deflection were measured. Three specimens were prepared and tested for each paste.
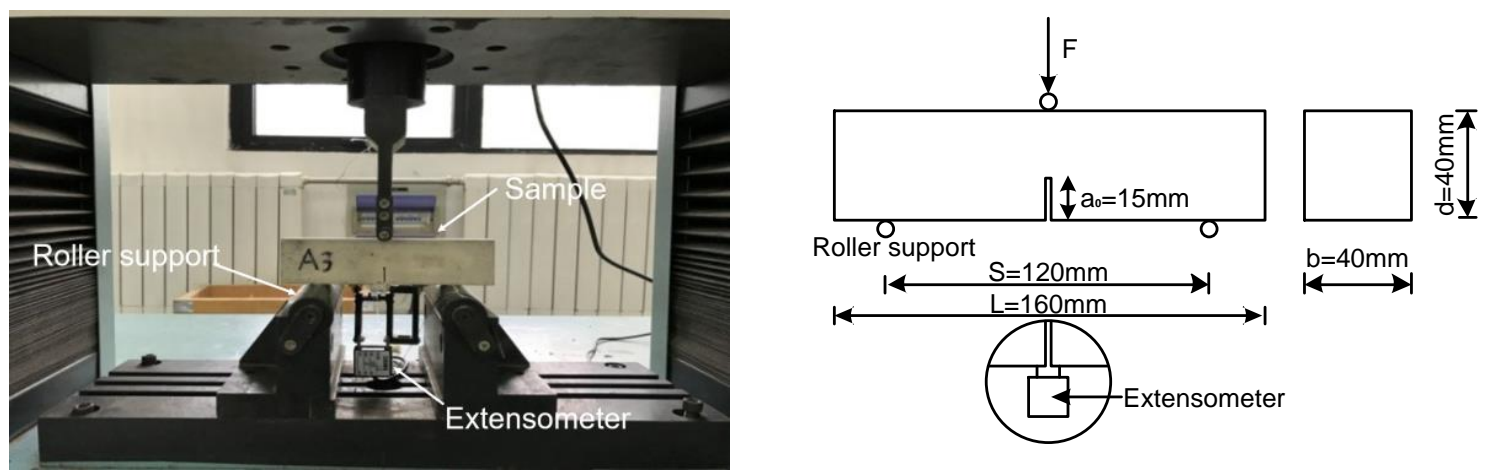

Figure 4. Three-point bending test setup and configuration.

Based on the area under the load-deflection curve, $G_{F}$ can be calculated using the following equation $[37,38]$ :

$$
G_{F}=\frac{A_{0}+m g \delta_{0}}{\left(d-a_{0}\right) b}
$$

where $A_{0}$ is the area under the load-deflection curves, $m g$ is the weight of the sample, $\delta_{0}$ is the deflection of the beam at final failure, $b$ is the beam width, $d$ is the depth, and $a_{0}$ is the notch depth. $E$ was calculated based on the initial linear elastic segment of the load-CMOD curves [37]. $\sigma_{\mathrm{t}}$ was calculated from the peak load results [39].

The microstructure of the fracture surface was characterized using SEM to observe the dispersion of the MWCNTs in the hardened pastes.

\section{Results and Discussion}

\subsection{Stabilizing Effect of HA on the Dispersion of MWCNTs in an Alkaline Environment}

Figure 5 presents the MWCNT suspensions with different HA/S in an alkaline pore solution and an aqueous solution at different times after ultrasonication. Visual observations show that all the prepared suspensions possessed a uniform black color. Re-agglomeration and sedimentation of MWCNTs in the suspensions occurred after settling for $3 \mathrm{~h}$, especially for the suspensions in the alkaline pore solution without HA. After $18 \mathrm{~h}$, most of the MWCNTs settled to the bottom and the color of the aqueous solutions became gray with greater transparency. The suspensions in pore solutions with HA/S of $0.12 \mathrm{wt}$.\% remained darker in color than the suspensions in alkaline pore solutions with other values of $\mathrm{HA} / \mathrm{S}$, indicating that more MWCNTs were in dispersion. 
(a)

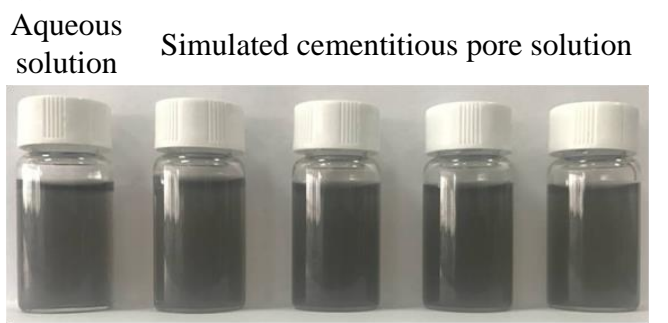

HA concentrations:

$0.00 \mathrm{wt} \% 0.00 \mathrm{wt} \% \quad 0.12 \mathrm{wt} \% \quad 0.25 \mathrm{wt} \% \quad 0.50 \mathrm{wt} \%$

(c)

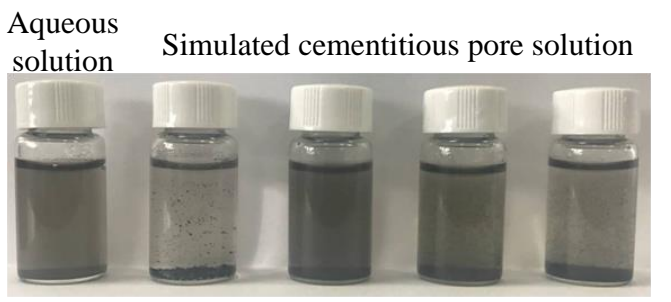

HA concentrations:

$0.00 \mathrm{wt} \% 0.00 \mathrm{wt} \% \quad 0.12 \mathrm{wt} \% \quad 0.25 \mathrm{wt} \% \quad 0.50 \mathrm{wt} \%$ (b)

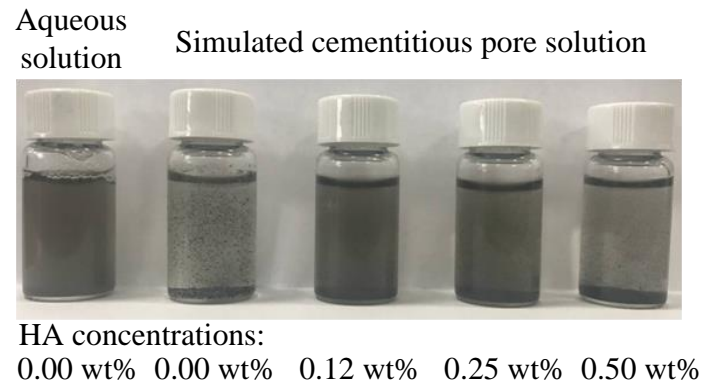

(d)

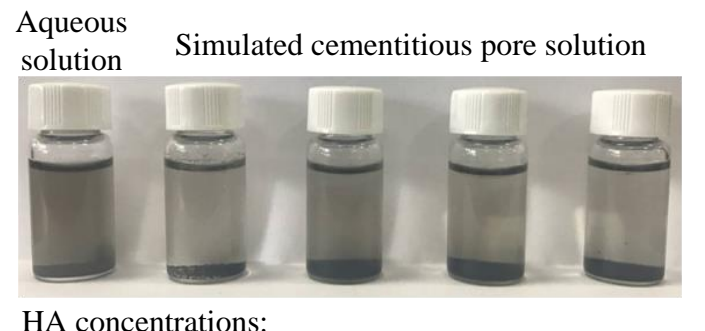

$0.00 \mathrm{wt} \% \quad 0.00 \mathrm{wt} \% \quad 0.12 \mathrm{wt} \% \quad 0.25 \mathrm{wt} \% \quad 0.50 \mathrm{wt} \%$

Figure 5. MWCNT suspensions containing different concentrations of humic acid (HA) in cementitious pore solutions and aqueous solution at different times: (a) $0 \mathrm{~h}$; (b) $3 \mathrm{~h}$; (c) $6 \mathrm{~h}$; (d) $18 \mathrm{~h}$ after ultrasonication.

Figure 6a shows the calculated $C_{d} / C_{t}$ over time using Equation (1), based on UV-vis measurements. $C_{\mathrm{d}} / C_{\mathrm{t}}$ quantifies the degree of dispersion, and a higher ratio means more MWCNTs are in the dispersed state [19]. Figure 6a shows that the dispersion of MWCNTs in aqueous solution is very stable, with the $C_{d} / C_{t}$ decreasing by less than $9 \%$ after $18 \mathrm{~h}$. In contrast, an obvious decline in $C_{d} / C_{t}$ is observed in other curves in Figure $6 \mathrm{a}$, indicating that the addition of a simulated pore environment reduces the degree of MWCNT dispersion. Over time, more MWCNTs tend to re-agglomerate, and $C_{d} / C_{t}$ decreases constantly to less than $40 \%$ after $18 \mathrm{~h}$. Before $15 \mathrm{~h}$, however, suspensions with $\mathrm{HA} / \mathrm{S}$ of $0.12 \mathrm{wt} \%$ are found to maintain more dispersed MWCNTs, increasing the stability by $21.9-45.8 \%$ compared to no HA.
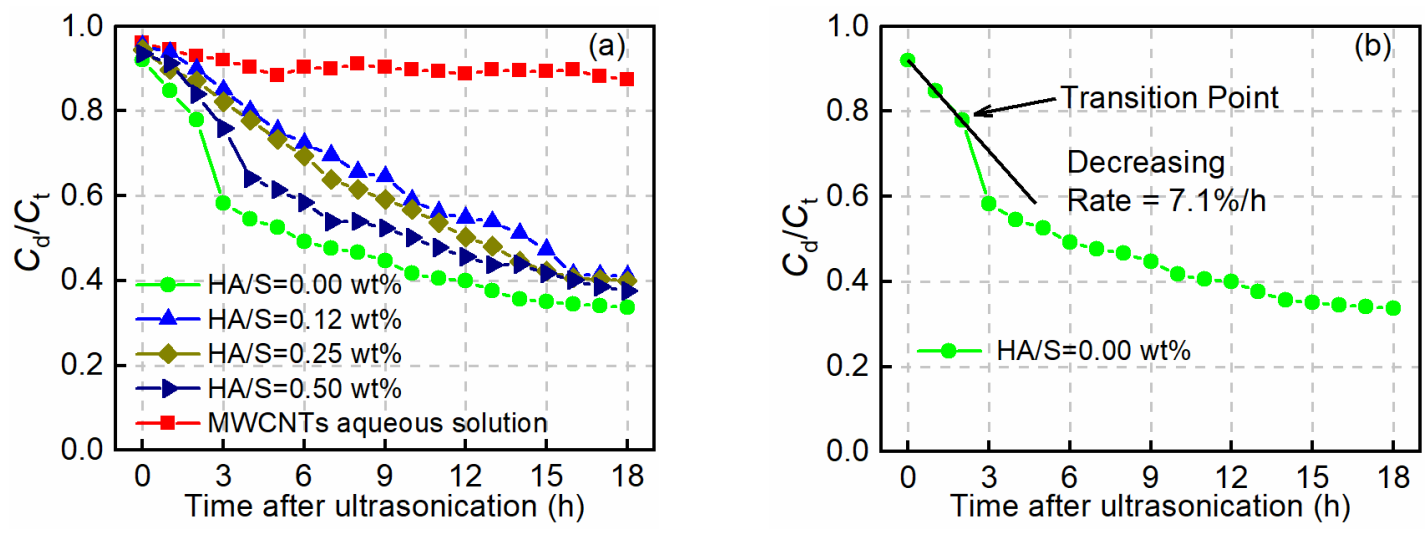

Figure 6. (a) Stabilization of MWCNT dispersion in different solutions after mixing; (b) determination of the transition point and decreasing rate of $C_{\mathrm{d}} / C_{\mathrm{t}}$. (Note: For clarity of presentation, the error bars are not presented.).

It is generally accepted that for cementitious mixtures with $w / c$ of $0.4-0.6$, the initial setting happens at about 3-4 h [19] and after that, the dispersion degree of MWCNTs will be less affected. At $3 \mathrm{~h}$, the dispersion degree of MWCNT suspensions containing $0.12 \mathrm{wt} . \% \mathrm{HA}$ is about $85 \%$, whereas that of MWCNT suspensions without HA is about $58 \%$. When HA/S exceeds $0.12 \mathrm{wt} . \%$, the dispersion 
degree declines by $89-97 \%$ compared to that of suspensions with HA/S of $0.12 \mathrm{wt} . \%$, indicating that an optimum mass concentration range of $\mathrm{HA}$ is required for achieving the maximum stabilizing effect. Because HA is a biomacromolecule and will absorb onto the surface of MWCNTs at a low concentration, which contributes to the increment of the steric repulsion in suspensions [40], the van der Waals forces will decrease and consequently delay the re-aggregation of MWCNTs [41,42]. However, when the HA/S exceeds $0.12 \mathrm{wt}$ \%, more adsorption of HA becomes less effectual for dispersion due to HA having a moderate molecular weight $(308.24 \mathrm{~g} / \mathrm{mol})$ and containing abundant functional groups [43] that might link adjacent MWCNTs into large agglomerations [44,45].

Figure $6 \mathrm{~b}$ shows a transition point during the decline of $C_{\mathrm{d}} / C_{\mathrm{t}}$, which can be identified by the curve's gradient. As shown in Figure 6b, before the transition point, the decrease of $C_{d} / C_{t}$ can be regarded as linear (7.1\% per hour for MWCNT suspensions without $\mathrm{HA})$, whereas after the transition point, $C_{\mathrm{d}} / C_{\mathrm{t}}$ experiences its maximum decrease in the $18 \mathrm{~h}$ period. The corresponding time for each transition point is measured for all curves (except MWCNTs in aqueous solution) in Figure 6a and listed in Table 3. Decreasing rates of $C_{\mathrm{d}} / C_{\mathrm{t}}$ are also found using linear regression (Table 3, column 3). The rate of decrease is affected by the HA concentration, and a moderate concentration of HA enhances the steric repulsion and stability of suspensions in an alkaline environment $[46,47]$. Furthermore, the transition points are obviously delayed by adding HA, especially at $0.12 \mathrm{wt} . \%$ HA concentration, which had a transition point at $9 \mathrm{~h}$.

Table 3. Transition time in the dispersion state.

\begin{tabular}{ccc}
\hline HA Concentration (wt.\%) & Transition Point (h) & Rate of Decrease of $C_{\mathbf{d}} / C_{\mathbf{t}}(\%$ per h) \\
\hline 0.00 & 2 & 7.1 \\
0.12 & 9 & 3.4 \\
0.25 & 6 & 4.2 \\
0.50 & 3 & 5.9 \\
\hline
\end{tabular}

\subsection{Effect of HA on the Workability of Fresh MWCNT-OPC Pastes}

The mini-slump spread versus HA/G is shown in Figure 7a, from which it can be seen that the spread diameter of plain or MWCNT-OPC pastes decreases gradually as HA/G increases from $0.00 \mathrm{wt} . \%$ to $0.20 \mathrm{wt} . \%$. For the plain OPC pastes, the slump diameter declined to $117.6 \mathrm{~mm}$ from $136.8 \mathrm{~mm}$ when $0.20 \mathrm{wt} . \%$ of HA was added. The adverse effect of HA on the workability of OPC is due to the adsorption between HA and PC becoming kinetically less favorable [48], resulting in electrostatic repulsion and elevated steric [22] hindrance between the collector surface and HA, thus inhibiting the workability of fresh pastes.
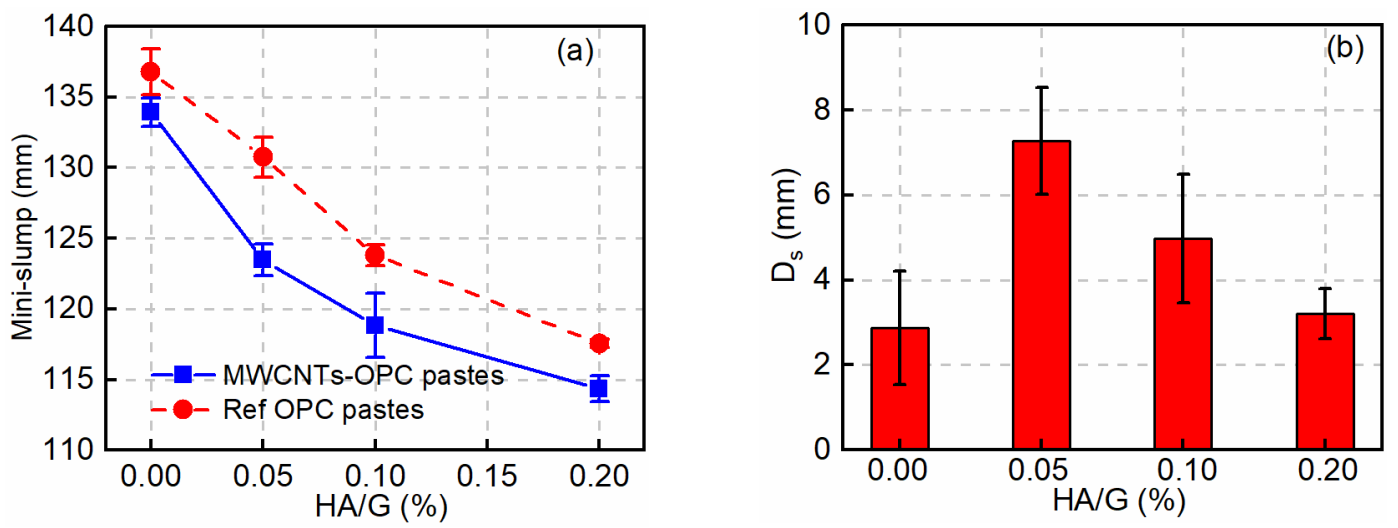

Figure 7. (a) Mini-slump spreads of fresh MWCNT-OPC and plain OPC pastes; (b) deterioration of slump diameter $\left(D_{\mathrm{s}}\right)$ caused by MWCNTs at different HA/G. 
As can be seen from Figure 7a, adding MWCNTs to the OPC pastes leads to a more significant decrease in the mini-slump diameter. The further deterioration in workability is affected by two factors: The first factor is that MWCNTs can act as nucleation sites to accelerate the hydration reaction and therefore decrease the workability of pastes [49]; the second factor is that the dispersed MWCNTs can absorb PC molecules [18], resulting in a decreased amount of PC interacting with cement powders in the MWCNT pastes than in the Ref pastes. Figure $7 \mathrm{~b}$ shows the deterioration of slump diameter $\left(D_{\mathrm{s}}\right)$ influenced by mixing MWCNTs at the same concentration of HA/G. The maximum deterioration of the slump diameter at $0.05 \mathrm{wt}$ \% HA/G is $7.2 \mathrm{~mm}$, decreasing from $130.7 \mathrm{~mm}$ for the Ref paste to $123.5 \mathrm{~mm}$ for the MWCNT-OPC paste. This is likely due to more MWCNTs being in a dispersed state at 0.12 wt.\% HA/S (discussed in Section 3.1), accelerating a stronger hydration reaction and absorbing more PC molecules.

\subsection{Effect of HA on the Mechanical Properties of MWCNT-OPC Pastes}

The average values of the compressive strength $\left(\sigma_{\mathrm{c}}\right)$ and flexural strength $\left(\sigma_{\mathrm{t}}\right)$ and their variations versus HA/G are presented in Figure 8. $\sigma_{\mathrm{c}}$ and $\sigma_{\mathrm{t}}$ of Ref pastes without any MWCNTs vary within the range of 49.1-52.3 $\mathrm{MPa}$ and 6.5-6.9 $\mathrm{MPa}$, respectively, with a maximum variation of about $6 \%$. This observation indicates that the addition of HA contributes little to the ultimate strength performance of cement pastes.
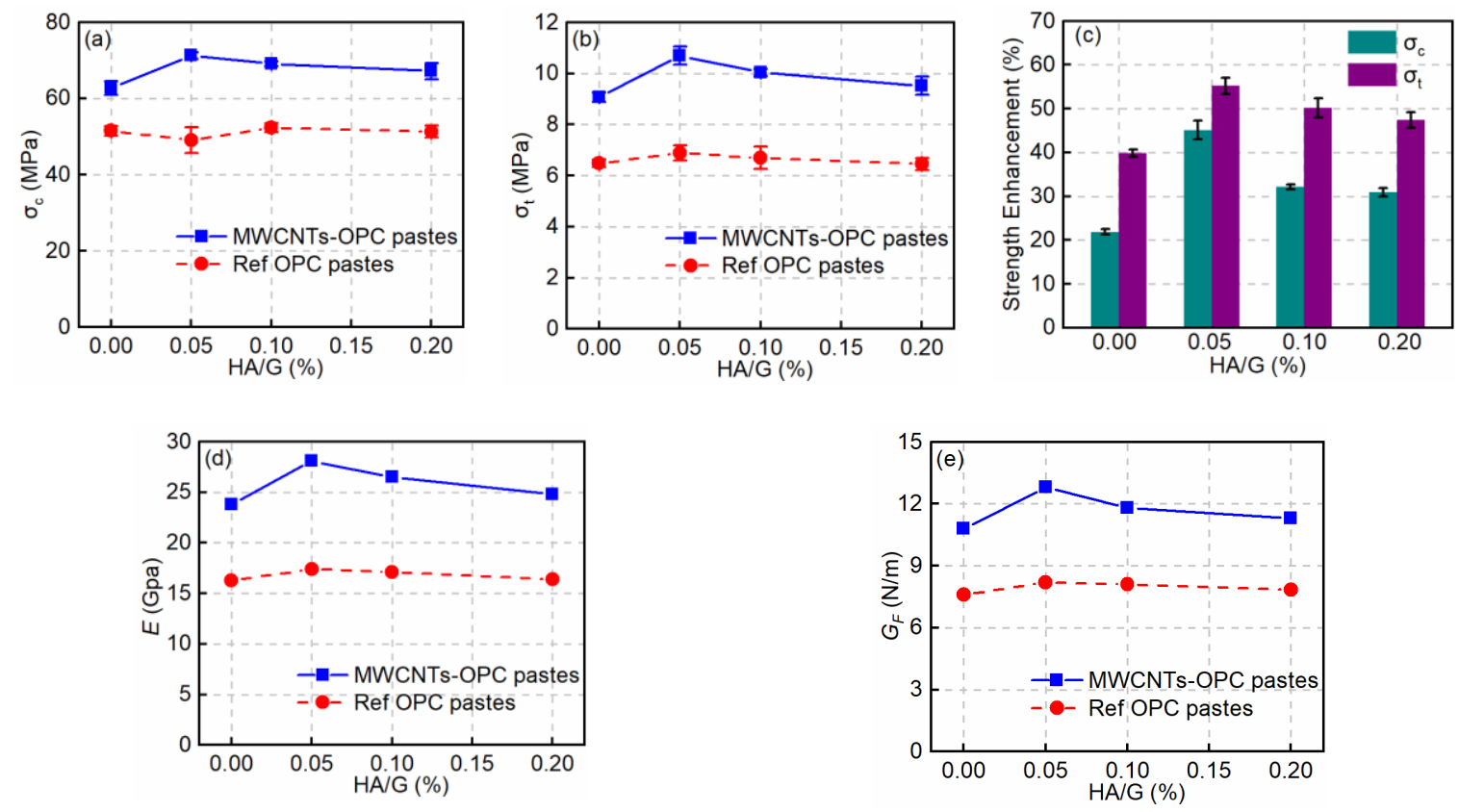

Figure 8. Variations of: (a) $\sigma_{\mathrm{c}}$ and (b) $\sigma_{\mathrm{t}}$ of cement pastes at the age of 28 days versus concentration of $\mathrm{HA}$; (c) Strength enhancement percent versus concentration of $\mathrm{HA}$; (d) $E$ and (e) $G_{F}$ of cement pastes at the age of $28 \mathrm{~d}$ versus concentration of HA. (Note: Due to the error bars in Figure d,e being too small, for clarity of presentation they are not presented).

After adding the MWCNTs to the OPC pastes, $\sigma_{\mathrm{c}}$ and $\sigma_{\mathrm{t}}$ of all samples increased. Since both the addition of PC [13] and HA makes little difference to the ultimate strength of cement matrices when the $w / c$ is constant, the improved mechanical properties of the hardened pastes are mainly due to the addition of MWCNTs. For MWCNT-OPC pastes, $\sigma_{\mathrm{c}}$ ranges from 62.8 to $71.2 \mathrm{MPa}$ and $\sigma_{\mathrm{t}}$ from 9.1 to 10.7 $\mathrm{MPa}$, increasing by about $22-45 \%$ and $40-55 \%$, respectively, when HA was added. As can be seen from Figure $8 \mathrm{~d}$,e, the overall variations of $E$ and $G_{\mathrm{F}}$ against $\mathrm{HA} / \mathrm{G}$ are correlated. It is found that the $E$ and $G_{F}$ increase with mixing HA. The optimal ranges of HA/G for improving ductility and fracture energy are found to be $0.05-0.10$. Compared with the control sample without HA, the maximum enhancement achieved with HA is found at 0.05 , where $E$ and $G_{\mathrm{F}}$ are improved by about $56.1-61.5 \%$. 
Figure $8 \mathrm{c}$ shows that the maximum increment of strength enhancement was achieved at an $\mathrm{HA} / \mathrm{G}$ of $0.05 \mathrm{wt} . \%$. The maximum increments of $\sigma_{\mathrm{c}}$ and $\sigma_{\mathrm{t}}$ are about $45 \%$ and $55 \%$, respectively. With more HA added to the OPC pastes, the enhancement effect is lower than that of the optimal concentration range. This finding is in accordance with the dispersion degree of the MWCNTs shown in Figure 8a. When there is no HA (HA/G $=0.00 \mathrm{wt} . \%$ ) or too much HA (HA/G $=0.20 \mathrm{wt} . \%)$, the stable dispersion of MWCNTs in an alkaline environment is decreased. Therefore, the enhancing efficiency of MWCNTs on $\sigma_{\mathrm{c}}$ and $\sigma_{\mathrm{t}}$ becomes poorer when HA/G is $0.00 \mathrm{wt} \%$ or $0.20 \mathrm{wt} \%$. An appropriate amount of HA (0.05 wt.\% to $0.10 \mathrm{wt} \%$ ) is beneficial for the uniform dispersion of MWCNTs (Figure 6) and correspondingly enhances the $\sigma_{\mathrm{c}}$ and $\sigma_{\mathrm{t}}$ of the specimens (Figure 8).

\subsection{Distribution of MWCNTs in the OPC Matrix}

In addition to mechanical performance reinforcement, MWCNTs can also influence the microstructure of the cement pastes, which is also linked with the long-term performance of the composite materials [50,51]. Previous research has suggested that MWCNTs can fill nano/micro-sized pores [15,52]. Nanomaterials may fill gel pores between calcium silicate hydrate products, contributing to a reduction in the porosity and an increment in stiffness $[15,52,53]$. On the other hand, MWCNTs can bridge capillary pores and enhance higher load capacity, ductility, and fracture energy of the cement pastes [53]. However, the agglomeration of MWCNTs may heavily decrease the function of nanomaterials and degrade strength performance $[9,13]$. To better investigate the reinforcing potential of HA benefiting the dispersion stabilization of MWCNTs in cement composites, the fracture surface of the sample was observed under SEM.

As presented in Figure 9a, the agglomeration of MWCNTs appears around the hydration products in one pore, while there are hardly any MWCNTs visible in other pores. The observation of the aggregation of MWCNTs is consistent with the measured $C_{d} / C_{t}$ (Figure 6a) in Section 3.1. Furthermore, the agglomerations are likely the cause of the clumped MWCNTs and "pulled-out" MWCNTs shown in Figure 9b, which are in turn the cause of the decreased mechanical properties, as presented in Section 3.3 [13].
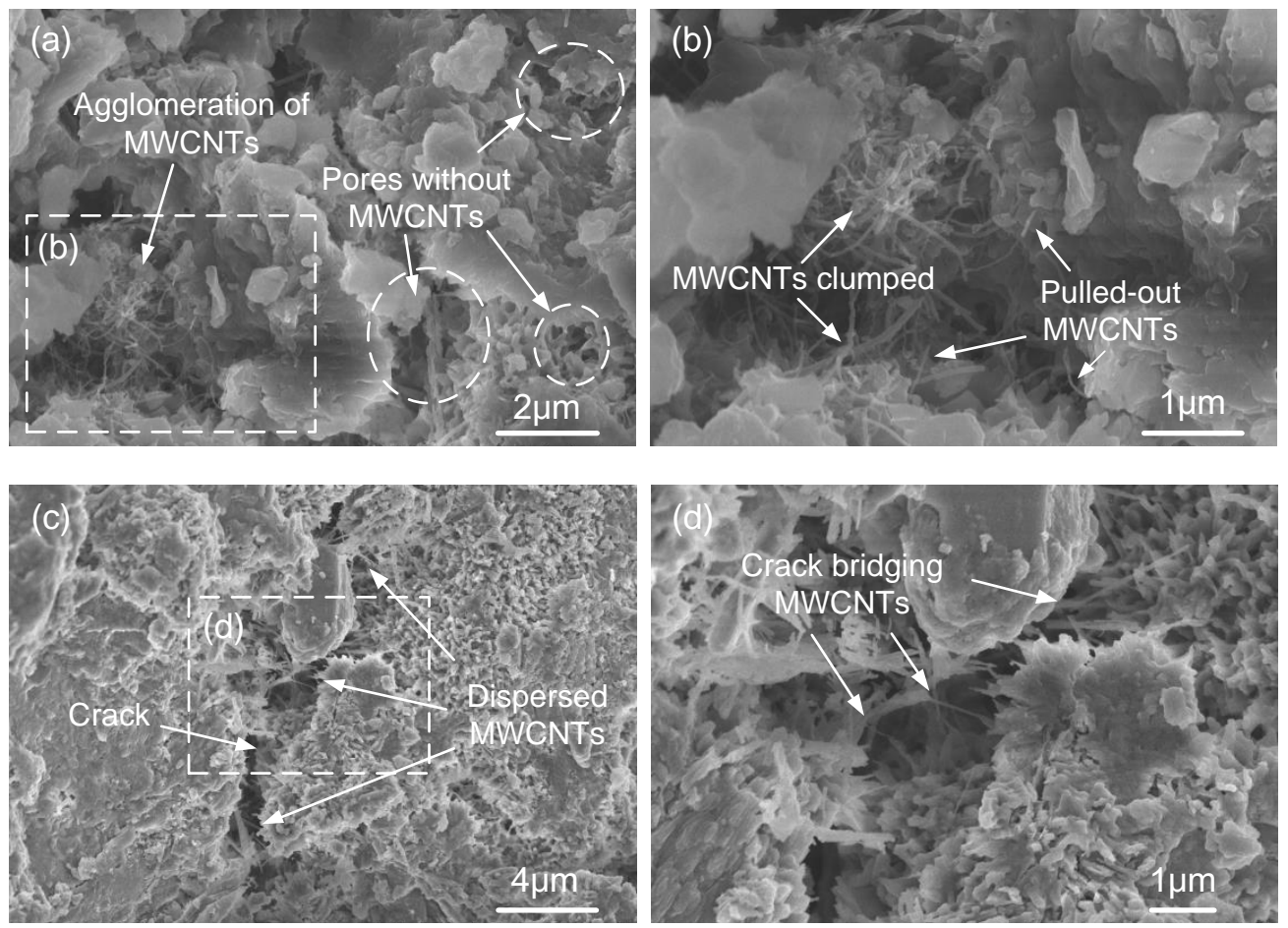

Figure 9. Scanning electron microscope (SEM) images of MWCNTs in the cement matrix with: $(\mathbf{a}, \mathbf{b})$ $\mathrm{HA} / \mathrm{G}=0.00$ wt. $\%$; (c,d) HA/G $=0.05$ wt. $\%$. 
Figure 9c,d show that the observable agglomerations of MWCNTs are markedly reduced at $0.05 \mathrm{wt} . \% \mathrm{HA} / \mathrm{G}$. Several cracks can be seen on the surface of the cement paste where an appropriate amount of dispersed MWCNTs is exposed. Moreover, a large amount of MWCNTs with sufficient length can bridge capillary cracks or pores (at the nano/micrometer scale) $[52,53]$, indicating that the well-dispersed MWCNTs could act as a crack bridging material and have the capacity to inhibit crack propagation, therefore providing improved mechanical performance of the cement matrix, as discussed in Section 3.3.

This study was consistent with the dispersion stabilization measurements and with the viewpoints presented in previous research: more dispersed MWCNTs implies that the tube-paste interfacial bonding is stronger, possibly resulting from the covalent bonds formed between the crack bridging MWCNTs and the pastes [13,52]. The unique capability of HA suggests that the combination of HA and MWCNTs may have the potential to reinforce both the strength and the ductility of cement pastes.

\section{Conclusions}

This study investigated the effects of HA on the dispersion of MWCNT suspensions in an alkaline environment and the workability and mechanical properties of MWCNT-OPC pastes. The main findings are as follows:

(1) The addition of HA works effectively for stabilizing the dispersion degree of MWCNT suspensions. The addition of $0.12 \mathrm{wt} . \% \mathrm{HA}$ gave the best performance in stabilizing the MWCNT dispersion in an alkaline environment, increasing the stability by $21.9-45.8 \%$.

(2) The addition of HA decreases the workability of OPC pastes, whereas it has little influence on the mechanical properties of the hardened OPC.

(3) HA can affect the mechanical performance of MWCNT-reinforced OPC pastes by influencing the dispersion degree of the MWCNTs. An appropriate range of the mass concentration of HA $(0.05-0.10 \mathrm{wt} . \%)$ is required to achieve optimum enhancing efficiency of the MWCNTs. The maximum increments in the compressive strength, flexural strength, Young's modulus, and fracture energy are $45 \%, 55 \%, 61 \%$ and $56 \%$, respectively.

(4) HA markedly improves the degree of dispersion of MWCNT suspensions by absorbing onto the surface of MWCNTs at a low concentration by enhancing the steric repulsion. The combination of HA may decrease the van der Waals forces among MWCNTs and inhibit the re-aggregation of MWCNTs. The SEM images show that the MWCNTs were distributed more uniformly in the cement matrices when HA was incorporated.

Author Contributions: Y.G., H.J. and M.D. conceived and designed the experiments; Y.G., M.D. and W.C. performed the experiments; Y.G., and W.C. analyzed the data; Y.G. and H.J. wrote the paper; and all four authors revised the paper.

Funding: This study was supported by the State Key Program of the National Natural Science of China (Grant No. 51734009).

Conflicts of Interest: The authors declare no conflict of interest.

\section{References}

1. Iijima, S. Helical microtubules of graphitic carbon. Nature 1991, 354, 56-58. [CrossRef]

2. Volder, M.F.L.D.; Tawfick, S.H.; Baughman, R.H.; Hart, A.J. Carbon nanotubes: Present and future commercial applications. Science 2013, 339, 535-539. [CrossRef] [PubMed]

3. Yu, M.F.; Lourie, O.; Dyer, M.J.; Moloni, K.; Kelly, T.F.; Ruoff, R.S. Strength and breaking mechanism of multiwalled carbon nanotubes under tensile load. Science 2000, 287, 637-640. [CrossRef] [PubMed]

4. Ruoff, R.S.; Lorents, D.C. Mechanical and thermal properties of carbon nanotubes. Carbon 1995, 33, 925-930. [CrossRef]

5. Ebbesen, T.W.; Lezec, H.J.; Hiura, H.; Bennett, J.W.; Ghaemi, H.F.; Thio, T. Electrical conductivity of individual carbon nanotubes. Nature 1996, 382, 54-56. [CrossRef] 
6. Gojny, F.H.; Wichmann, M.H.G.; Fiedler, B.; Schulte, K. Influence of different carbon nanotubes on the mechanical properties of epoxy matrix composites-a comparative study. Compos. Sci. Technol. 2005, 65, 2300-2313. [CrossRef]

7. Harrison, B.S.; Atala, A. Carbon nanotube applications for tissue engineering. Biomaterials 2007, 28, 344-353. [CrossRef] [PubMed]

8. Xia, Z.; Riester, L.; Curtin, W.A.; Li, H.; Sheldon, B.W.; Liang, J.; Chang, B.; Xu, J.M. Direct observation of toughening mechanisms in carbon nanotube ceramic matrix composites. Acta Mater. 2004, 52, 931-944. [CrossRef]

9. Coleman, J.N.; Khan, U.; Blau, W.J.; Gun Ko, Y.K. Small but strong: A review of the mechanical properties of carbon nanotube-polymer composites. Carbon 2006, 44, 1624-1652. [CrossRef]

10. Li, W.; Ji, W.; Torabian, I.F.; Wang, Y.; Li, G.; Liu, Y.; Xing, F. Nano-silica sol-gel and carbon nanotube coupling effect on the performance of cement-based materials. Nanomaterials 2017, 7, 185. [CrossRef] [PubMed]

11. Wang, L.; Zheng, D.; Zhang, S.; Cui, H.; Li, D. Effect of $\mathrm{Nano}^{-S i O}{ }_{2}$ on the hydration and microstructure of portland cement. Nanomaterials 2016, 6, 241. [CrossRef] [PubMed]

12. Szelag, M. Mechano-physical properties and microstructure of carbon nanotube reinforced cement paste after thermal load. Nanomaterials 2017, 7, 267. [CrossRef] [PubMed]

13. Zou, B.; Chen, S.J.; Korayem, A.H.; Collins, F.; Wang, C.M.; Duan, W.H. Effect of ultrasonication energy on engineering properties of carbon nanotube reinforced cement pastes. Carbon 2015, 85, 212-220. [CrossRef]

14. Xu, S.; Liu, J.; Li, Q. Mechanical properties and microstructure of multi-walled carbon nanotube-reinforced cement paste. Constr. Build. Mater. 2015, 76, 16-23. [CrossRef]

15. Konsta-Gdoutos, M.S.; Metaxa, Z.S.; Shah, S.P. Highly dispersed carbon nanotube reinforced cement based materials. Cem. Concr. Res. 2010, 40, 1052-1059. [CrossRef]

16. Girifalco, L.A.; Hodak, M.; Lee, R.S. Carbon nanotubes, buckyballs, ropes, and a universal graphitic potential. Phys. Rev. B 2000, 62, 13104-13110. [CrossRef]

17. Islam, M.F.; Rojas, E.; Bergey, D.M.; Johnson, A.T.; Yodh, A.G. High Weight-Fraction surfactant solubilization of Single-Wall carbon nanotubes in water. Nano Lett. 2003, 3, 269-273. [CrossRef]

18. Collins, F.; Lambert, J.; Duan, W.H. The influences of admixtures on the dispersion, workability, and strength of carbon nanotube-OPC paste mixtures. Cem. Concr. Compos. 2012, 34, 201-207. [CrossRef]

19. Chen, S.J.; Wang, W.; Sagoe-Crentsil, K.; Collins, F.; Zhao, X.L.; Majumder, M.; Duan, W. Distribution of carbon nanotubes in fresh ordinary Portland cement pastes: Understanding from a two-phase perspective. RSC Adv 2016, 6, 5745-5753. [CrossRef]

20. Rajabipour, F.; Sant, G.; Weiss, J. Interactions between shrinkage reducing admixtures (SRA) and cement paste's pore solution. Cem. Concr. Res. 2008, 38, 606-615. [CrossRef]

21. Ghods, P.; Isgor, O.B.; Mcrae, G.; Miller, T. The effect of concrete pore solution composition on the quality of passive oxide films on black steel reinforcement. Cem. Concr. Compos. 2009, 31, 2-11. [CrossRef]

22. Du, M.R.; Jing, H.W.; Duan, W.H.; Han, G.S.; Chen, S.J. Methylcellulose stabilized multi-walled carbon nanotubes dispersion for sustainable cement composites. Constr. Build. Mater. 2017, 146, 76-85. [CrossRef]

23. Rosquoët, F.; Alexis, A.; Khelidj, A.; Phelipot, A. Experimental study of cement grout: Rheological behavior and sedimentation. Cem. Concr. Res. 2003, 33, 713-722. [CrossRef]

24. Fan, L.; Harris, J.L.; Roddick, F.A.; Booker, N.A. Influence of the characteristics of natural organic matter on the fouling of microfiltration membranes. Water Res. 2001, 35, 4455-4463. [CrossRef]

25. Saleh, N.B.; Pfefferle, L.D.; Elimelech, M. Aggregation kinetics of multiwalled carbon nanotubes in aquatic systems: Measurements and environmental implications. Environ. Chem. 2015, 42, 7963-7969. [CrossRef]

26. Han, Y.; Hwang, G.; Park, S.; Gomezflores, A.; Jo, E.; Eom, I.C.; Tong, M.; Kim, H.J.; Kim, H. Stability of carboxyl-functionalized carbon black nanoparticles: The role of solution chemistry and humic acid. Environ. Sci.-Nano 2017, 4. [CrossRef]

27. Yang, K.; Xing, B. Adsorption of fulvic acid by carbon nanotubes from water. Environ. Pollut. 2009, 157, 1095. [CrossRef] [PubMed]

28. Hyung, H.; Fortner, J.D.; Hughes, J.B.; Kim, J.H. Natural organic matter stabilizes carbon nanotubes in the aqueous phase. Environ. Sci. Technol. 2007, 41, 179-184. [CrossRef] [PubMed]

29. Yang, M.; Li, Z.; Liu, Y.; Ma, S.; Chen, J. Impacts and mechanisms of natural organic matter and $\mathrm{pH}$ on the transport of nanobiochar. Geoscience 2018, 32, 113-120. [CrossRef] 
30. Common Portland Cement; Chinese National Standard GB/T 175-2007; Standards Press of China: Beijing, China, 9 Novemeber 2007.

31. Li, X.; Korayem, A.H.; Li, C.; Liu, Y.; He, H.; Sanjayan, J.G.; Wen, H.D. Incorporation of graphene oxide and silica fume into cement paste: A study of dispersion and compressive strength. Constr. Build. Mater. 2017, 123, 327-335. [CrossRef]

32. Grossiord, N.; Regev, O.; Loos, J.; Meuldijk, J.; Koning, C.E. Time-dependent study of the exfoliation process of carbon nanotubes in aqueous dispersions by using UV-visible spectroscopy. Anal. Chem. 2005, 77, 5135-5139. [CrossRef] [PubMed]

33. Yu, J.; Grossiord, N.; Koning, C.E.; Loos, J. Controlling the dispersion of multi-wall carbon nanotubes in aqueous surfactant solution. Carbon 2007, 45, 618-623. [CrossRef]

34. Hatami, F.; Masselink, W.T.; Harris, J.S. The quantitative characterization of the concentration and dispersion of multi-walled carbon nanotubes in suspension by spectrophotometry. Nanotechnology 2006, 17, 3692. [CrossRef]

35. Clark, M.D.; Jespersen, M.L.; Patel, R.J.; Leever, B.J. Predicting vertical phase segregation in polymer-fullerene bulk heterojunction solar cells by free energy analysis. ACS Appl. Mater. Interfaces 2013, 5, 4799-4807. [CrossRef] [PubMed]

36. Baskaran, D.; Mays, J.W.; Bratcher, M.S. Noncovalent and nonspecific molecular interactions of polymers with multiwalled carbon nanotubes. Chem. Mater. 2005, 17, 3389-3397. [CrossRef]

37. Recommendation, R.D. Determination of the fracture energy of mortar and concrete by means of three-point bend tests on notched beams. Mater. Struct. 1985, 18, 484. [CrossRef]

38. Hillerborg, A. The theoretical basis of a method to determine the fracture energy $\mathrm{G}_{\mathrm{F}}$ of concrete. Mater. Struct. 1985, 18, 291-296. [CrossRef]

39. Shah, S. Determination of fracture parameters $\left(\mathrm{K}_{\mathrm{Ic}}{ }^{\mathrm{s}}\right.$ and $\left.\mathrm{CTOD}_{\mathrm{c}}\right)$ of plain concrete using three-point bend test. Mater. Struct. 1900, 23, 457-460. [CrossRef]

40. Chen, K.L.; Elimelech, M. Influence of humic acid on the aggregation kinetics of fullerene (C60) nanoparticles in monovalent and divalent electrolyte solutions. J. Colloid Interface Sci. 2007, 309, 126-134. [CrossRef] [PubMed]

41. Bian, S.W.; Mudunkotuwa, I.A.; Rupasinghe, T.; Grassian, V.H. Aggregation and dissolution of $4 \mathrm{~nm} \mathrm{ZnO}$ nanoparticles in aqueous environments: Influence of $\mathrm{pH}$, ionic strength, size, and adsorption of humic acid. Langmuir 2011, 27, 6059-6068. [CrossRef] [PubMed]

42. Han, Y.; Kim, D.; Hwang, G.; Lee, B.; Eom, I.; Kim, P.J.; Tong, M.; Kim, H. Aggregation and dissolution of ZnO nanoparticles synthesized by different methods: Influence of ionic strength and humic acid. Colloid Surface. A 2014, 451, 7-15. [CrossRef]

43. Liu, W.; Zhao, X.; Cai, Z.; Han, B.; Zhao, D. Aggregation and stabilization of multiwalled carbon nanotubes in aqueous suspensions: Influences of carboxymethyl cellulose, starch and humic acid. RSC Adv. 2016, 6, 67260. [CrossRef]

44. Zhou, D.; Keller, A.A. Role of morphology in the aggregation kinetics of ZnO nanoparticles. Water Res. 2010, 44, 2948-2956. [CrossRef] [PubMed]

45. Keller, A.A.; Wang, H.; Zhou, D.; Lenihan, H.S.; Cherr, G.; Cardinale, B.J.; Miller, R.; Ji, Z. Stability and aggregation of metal oxide nanoparticles in natural aqueous matrices. Environ. Sci. Technol. 2010, 44, 1962-1967. [CrossRef] [PubMed]

46. Li, C.Z.; Feng, N.Q.; Li, Y.D.; Chen, R.J. Effects of polyethlene oxide chains on the performance of polycarboxylate-type water-reducers. Cem. Concr. Res. 2005, 35, 867-873. [CrossRef]

47. Nawa, T. Effect of chemical structure on steric stabilization of polycarboxylate-based superplasticizer. J. Struct. Constr. Eng. 2006, 66, 225-232. [CrossRef]

48. Han, B.; Zhang, M.; Zhao, D.; Feng, Y. Degradation of aqueous and soil-sorbed estradiol using a new class of stabilized manganese oxide nanoparticles. Water Res. 2015, 70, 288. [CrossRef] [PubMed]

49. Makar, J.M.; Chan, G.W. Growth of cement hydration products on single walled carbon nanotubes. J. Am. Ceram. Soc. 2010, 92, 1303-1310. [CrossRef]

50. Zhao, L.; Guo, X.; Ge, C.; Li, Q.; Guo, L.; Shu, X. Mechanical behavior and toughening mechanism of polycarboxylate superplasticizer modified graphene oxide reinforced cement composites. Compos. Part B-Eng. 2017, 113, 308-316. [CrossRef] 
51. Kim, H.-K. Chloride penetration monitoring in reinforced concrete structure using carbon nanotube/cement composite. Constr. Build. Mater. 2015, 96, 29-36. [CrossRef]

52. Li, G.Y.; Wang, P.M.; Zhao, X. Mechanical behavior and microstructure of cement composites incorporating surface-treated multi-walled carbon nanotubes. Carbon 2005, 43, 1239-1245. [CrossRef]

53. Han, B.; Yu, X.; Ou, J. Multifunctional and Smart Carbon Nanotube Reinforced Cement-Based Materials; Springer: Berlin/Heidelberg, Germany, 2011; pp. 1-47.

(C) 2018 by the authors. Licensee MDPI, Basel, Switzerland. This article is an open access article distributed under the terms and conditions of the Creative Commons Attribution (CC BY) license (http:/ / creativecommons.org/licenses/by/4.0/). 